Virginia Commonwealth University VCU Scholars Compass

2001

\title{
Geometry, electronic structure, and energetics of copper-doped aluminum clusters
}

\author{
S. N. Khanna \\ Virginia Commonwealth University \\ C. Ashman \\ Virginia Commonwealth University \\ B. K. Rao \\ Virginia Commonwealth University \\ P. Jena \\ Virginia Commonwealth University
}

Follow this and additional works at: http://scholarscompass.vcu.edu/phys_pubs

Part of the Physics Commons

Khanna, S. N., Ashman, C., Rao, B. K., et al. Geometry, electronic structure, and energetics of copper-doped aluminum clusters. The Journal of Chemical Physics 114, 9792 (2001). Copyright $@ 2001$ AIP Publishing LLC.

\section{Downloaded from}

http://scholarscompass.vcu.edu/phys_pubs/154

This Article is brought to you for free and open access by the Dept. of Physics at VCU Scholars Compass. It has been accepted for inclusion in Physics Publications by an authorized administrator of VCU Scholars Compass. For more information, please contact libcompass@vcu.edu. 


\title{
Geometry, electronic structure, and energetics of copper-doped aluminum clusters
}

\author{
S. N. Khanna, ${ }^{\text {a) }}$ C. Ashman, B. K. Rao, and P. Jena \\ Physics Department, Virginia Commonwealth University, Richmond, Virginia 23284-2000
}

(Received 5 February 2001; accepted 2 March 2001)

\begin{abstract}
Using density functional theory and generalized gradient approximation for exchange-correlation potential, we have calculated the equilibrium geometries and energetics of neutral and negatively charged $\mathrm{Al}_{n} \mathrm{Cu}(n=11,12,13,14)$ clusters. Unlike the alkali atom-doped aluminum clusters in the same size range, the copper atom resides inside the aluminum cluster cage. Furthermore, the $3 d$ and $4 s$ energy levels of $\mathrm{Cu}$ hybridize with the valence electrons of $\mathrm{Al}$ causing a redistribution of the molecular orbital energy levels of the $\mathrm{Al}_{n}$ clusters. However, this redistribution does not affect the magic numbers of $\mathrm{Al}_{n} \mathrm{Cu}$ clusters that could be derived by assuming that $\mathrm{Cu}$ donates one electron to the valence levels of $\mathrm{Al}_{n}$ clusters. This behavior, brought about by the smaller size and large ionization potential of the copper atom, contributes to the anomalous properties of $\mathrm{Al}_{n} \mathrm{Cu}^{-}$anions: Unlike $\mathrm{Al}_{n} \mathrm{X}^{-}\left(\mathrm{X}=\right.$ alkali atom), the mass ion intensities of $\mathrm{Al}_{n} \mathrm{Cu}^{-}$are similar to those of $\mathrm{Al}_{n}^{-}$. The calculated adiabatic electron affinities are also in very good agreement with experiment. (C) 2001 American Institute of Physics. [DOI: 10.1063/1.1367381]
\end{abstract}

\section{INTRODUCTION}

Since the pioneering work of Knight et al. ${ }^{1}$ exhibiting a direct relationship between the pronounced peaks in the mass ion intensities (commonly referred to as magic numbers) of $\mathrm{Na}$ clusters and electronic shell closure, considerable theoretical and experimental work has been carried out to search for new magic numbers in compounds as well as charged metal clusters. ${ }^{2}$ The electronic shell closure derived from the Jellium model dictates that metal clusters with $2,8,20,40, \ldots$ electrons are particularly stable as they correspond to complete filling of $1 s, 1 s 1 p, 1 s 1 p 1 d 2 s, 1 s 1 p 1 d 2 s 1 f$ $2 p, \ldots$ groups of orbitals, respectively. $\mathrm{As} \mathrm{Al}, \mathrm{Cu}$, and alkali metal atoms exhibit free-electron-like behavior in their respective bulk phases, one would expect the atomic and electronic structure as well as relative stabilities of copper-doped aluminum clusters to exhibit the same behavior as those of alkali atom-doped aluminum clusters ${ }^{3,4}$ since both clusters contain the same number of valence electrons. For example, if clusters are born neutral, $\mathrm{Al}_{13} \mathrm{Cu}$ clusters should exhibit enhanced stability (and, hence, a peak in the mass spectra) over their neighbors as it would contain 40 valence electrons. On the other hand, if clusters are born negatively charged the intensity of the mass spectra of $\mathrm{Al}_{n} \mathrm{Cu}^{-}$clusters should exhibit a dip at $n=13$ as these clusters contain one electron more than that needed for shell closing. This behavior has, indeed, been observed for $\mathrm{Al}_{13} \mathrm{X}^{-}(\mathrm{X}=$ alkali atom $)$ clusters. ${ }^{5}$

In a recent study of the mass ion intensity distribution of $\mathrm{Al}_{n} \mathrm{Cu}^{-}$clusters, Bowen and co-workers, ${ }^{6}$ however, observed a different behavior. The pronounced peaks corresponding to $\mathrm{Al}_{n} \mathrm{Cu}^{-}$were the same as those of $\mathrm{Al}_{n}^{-}$. This implies that the magic numbers in $\mathrm{Al}_{n}^{-}$clusters are not affected by copper doping. Consider, in particular, clusters of

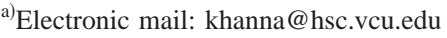

$\mathrm{Al}_{13}^{-}, \mathrm{Al}_{13} \mathrm{~K}$, and $\mathrm{Al}_{13} \mathrm{Cu}$. All three clusters have 40 valence electrons and $\mathrm{Al}_{13}^{-}$has been known ${ }^{7}$ to be highly abundant in the mass spectra. Since $\mathrm{Al}_{13} \mathrm{Cu}^{-}$and $\mathrm{Al}_{13} \mathrm{~K}^{-}$have 41 electrons, their mass ion intensity peaks should not have pronounced structures. Thus, the experimental observation that the peak intensity of $\mathrm{Al}_{13} \mathrm{Cu}^{-}$is higher than those of $\mathrm{Al}_{12} \mathrm{Cu}^{-}$and $\mathrm{Al}_{14} \mathrm{Cu}^{-}$seems anomalous. Similar effects were earlier observed in the magic numbers associated with $\mathrm{Na}_{n}$ and $\mathrm{Na}_{n} \mathrm{Mg}$ clusters ${ }^{8}$ where $\mathrm{Na}_{8} \mathrm{Mg}$ was found to be more stable than $\mathrm{Na}_{7} \mathrm{Mg}$ and $\mathrm{Na}_{9} \mathrm{Mg}$. It was shown ${ }^{9}$ that the doping of $\mathrm{Mg}$ into $\mathrm{Na}_{n}$ clusters led to a rearrangement of the molecular energy levels that, in turn, explained the observed abundance in the mass spectra.

To understand the anomalous behavior of the mass ion intensity in $\mathrm{Al}_{n} \mathrm{Cu}^{-}$vis-à-vis alkali metal atom-doped aluminum clusters, we have calculated the equilibrium geometry and total energy of neutral and anionic $\mathrm{Al}_{n} \mathrm{Cu}(n$ $=11,12,13,14)$ clusters using first principles theory. We show that unlike the alkali atoms, copper prefers to occupy internal sites in the aluminum clusters. This is because the size of the copper atom is smaller than that of aluminum. Second, the large ionization potential of $\mathrm{Cu}(7.72 \mathrm{eV})$ makes it energetically unfavorable to transfer its outermost $s$ electron to the $\mathrm{Al}_{n}$ cage and thus does not form an ionic bond between $\mathrm{Al}_{13}^{-}$and $\mathrm{Cu}^{+}$as is the situation with alkali metal atom-doped $\mathrm{Al}_{13}$ cluster. We find instead that analogous to $\mathrm{Na}_{n} \mathrm{Mg}$ clusters, the doping of copper modifies the molecular orbital energy levels. Consequently the mass ion intensity distribution of $\mathrm{Al}_{n} \mathrm{Cu}^{-}$shows the same magic numbers as $\mathrm{Al}_{n}^{-}$. We have also calculated vertical and adiabatic detachment energies of $\mathrm{Al}_{n} \mathrm{Cu}^{-}$clusters as well as the vertical ionization potentials of $\mathrm{Al}_{n} \mathrm{Cu}$ clusters. The low electron affinity and large highest occupied molecular orbital (HOMO)lowest unoccupied molecular orbital (LUMO) gap of $\mathrm{Al}_{13} \mathrm{Cu}$, in comparison to its neighboring clusters, indicate 
that $\mathrm{Al}_{13} \mathrm{Cu}$ corresponds to a closed electronic shell system in spite of the rearrangements of the molecular energy levels resulting from $\mathrm{Cu}$ doping. The calculated electron affinities of these clusters agree very well with experiment providing indirect evidence of the accuracy of the computed geometries. In the following we provide a brief outline of our computational procedure. A discussion of our results and a summary are given in Secs. III and IV, respectively.

\section{COMPUTATIONAL PROCEDURE}

The theoretical calculations were carried out within the density functional formalism using a linear combination of atomic orbitals molecular orbital approach. ${ }^{10}$ Here, the molecular orbitals are formed from a linear combination of atomic orbitals centered at the atomic sites. The atomic orbitals were represented by Gaussian functions and the exchange correlation contributions were included using a gradient corrected density functional recently proposed by Perdew et al. ${ }^{11}$ The actual calculations were done at the all electron level using the NRLMOL code developed by Pederson and Jackson. ${ }^{12}$ In this implementation, the multicenter integrals required to solve the Kohn-Sham equations are calculated by integrating numerically over a mesh of points. The basis set consisted of $6 s, 5 p$, and $3 d$ Gaussian functions for $\mathrm{Al}$ and $7 s, 5 p$, and $4 d$ Gaussian functions for $\mathrm{Cu}$. The atomic basis sets were supplemented by an additional $d$ function in each case. The basis sets used here are well tested and the reader is referred to earlier papers ${ }^{13}$ for details. Since the number of atoms in most of the clusters studied here do not correspond to a closed geometrical shell, determination of the ground state geometry can be a tedious task. To explore the vast configurational space, several initial configurations were tried and the geometry was optimized without symmetry constraint using a conjugated gradient approach. The final structures thus include possible Jahn-Teller distortions.

\section{RESULTS AND DISCUSSION}

Even though $\mathrm{K}$ and $\mathrm{Cu}$ are monovalent atoms belonging to the same row of the periodic table, their size and ionization potentials are different. While the radii of $\mathrm{K}^{+}$and $\mathrm{Cu}^{+}$ are 1.54 and $0.96 \AA$, respectively, the ionization potentials of $\mathrm{K}$ and $\mathrm{Cu}$ atoms are 4.34 and $7.72 \mathrm{eV}$, respectively. These differences in size and ionization potentials affect the properties of $\mathrm{Al}_{n} \mathrm{~K}$ and $\mathrm{Al}_{n} \mathrm{Cu}$ clusters both in neutral and charged configurations. For example, the binding energy and bond length of the $\mathrm{AlCu}$ dimer are, respectively, $2.42 \mathrm{eV}$ and $2.38 \AA$, while those of the AlK dimer are $0.62 \mathrm{eV}$ and 3.68 $\AA$, respectively. These differences persist to larger clusters as well. In $\mathrm{Al}_{n} \mathrm{~K}(n=12,13,14)$ clusters, $\mathrm{K}$ always resides outside the $\mathrm{Al}_{n}$ cluster cage. ${ }^{4}$ However, the situation is entirely different for $\mathrm{Al}_{n} \mathrm{Cu}$ clusters.

In Fig. 1 we present the equilibrium geometries of $\mathrm{Al}_{n} \mathrm{Cu}$ $(n=11,12,13,14)$ clusters in anionic and neutral configurations. Note that in all these clusters $\mathrm{Cu}$ resides inside the $\mathrm{Al}_{n}$ cage irrespective of their size and charge states. Both neutral and anionic $\mathrm{Al}_{11} \mathrm{Cu}$ clusters form a structure that is a precursor to an icosahedric structure. The $\mathrm{Al}_{12} \mathrm{Cu}$ cluster both in neutral and anionic forms is a slightly distorted icosahedron.
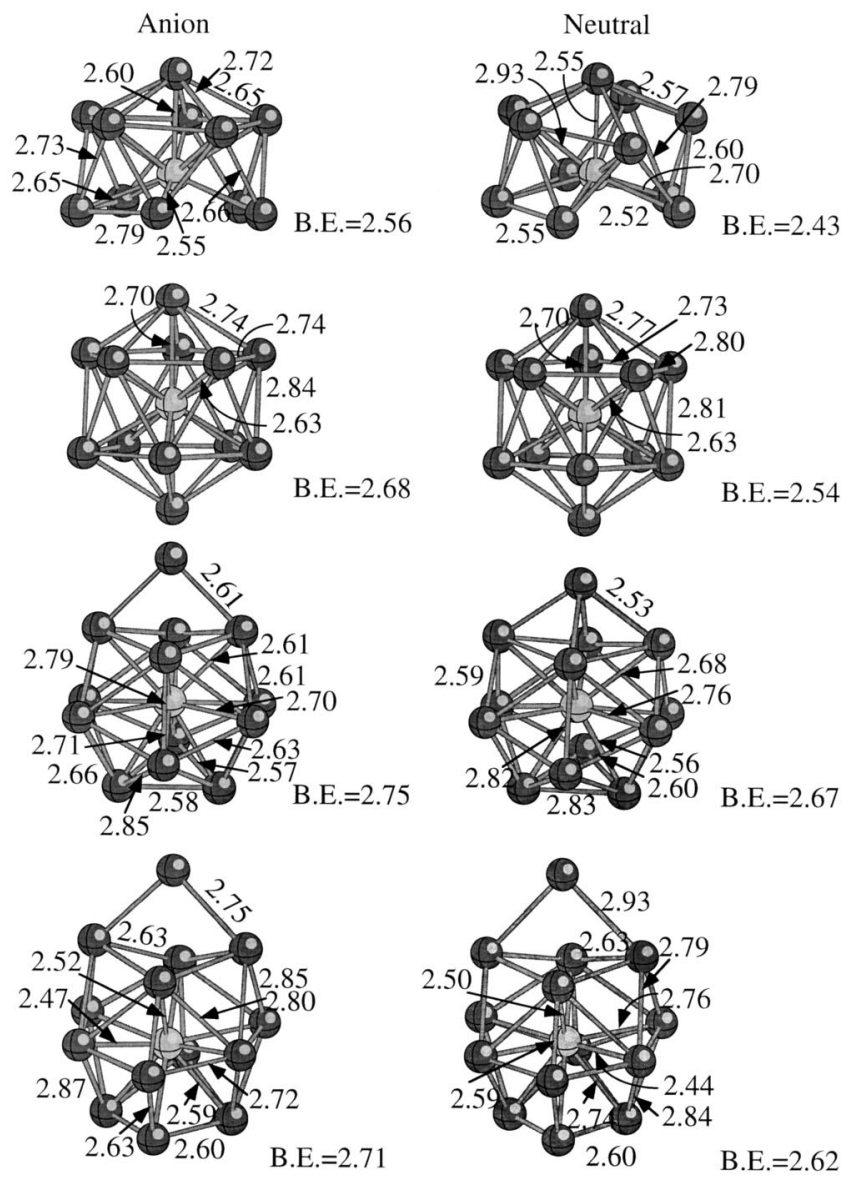

FIG. 1. Equilibrium geometries of neutral and anionic $\mathrm{Al}_{n} \mathrm{Cu}$ Clusters. The lighter spheres are the $\mathrm{Cu}$ atoms while the darker spheres are the $\mathrm{Al}$ sites. The bond lengths are in $\AA$ and the binding energies are in $\mathrm{eV}$.

In a perfect icosahedron there are 30 identical surface bonds that are 5\% elongated over the 12 identical radial bonds. Note that in $\mathrm{Al}_{12} \mathrm{Cu}$ clusters the surface bond lengths are not exactly equal to each other, as is the case with radial bonds. Moreover, $\mathrm{Cu}$ occupies the central position and remains there as more $\mathrm{Al}$ atoms are added. The $\mathrm{Al}_{13} \mathrm{Cu}$ cluster is noticeably distorted from an icosahedric form both in neutral and anionic forms. In contrast, the structure of $\mathrm{Al}_{13} \mathrm{~K}$ is that of a nearly perfect $\mathrm{Al}_{13}$ icosahedric cluster ${ }^{14}$ with the $\mathrm{K}$ atom residing outside the cage at a threefold coordinated site. Similarly, the structure of $\mathrm{Al}_{14} \mathrm{Cu}$ is very different from that of $\mathrm{Al}_{14} \mathrm{~K}$. In $\mathrm{Al}_{14} \mathrm{~K}$ one of the $\mathrm{Al}$ atoms and the $\mathrm{K}$ atom attach to the $\mathrm{Al}_{13}$ icosahedric cage at opposite ends. The icosahedric motif is broken in the $\mathrm{Al}_{14} \mathrm{Cu}$ cage with the $\mathrm{Cu}$ atom residing in the interior.

In Table I we list the total energies of optimized $\mathrm{Al}_{n} \mathrm{Cu}^{-}$ and $\mathrm{Al}_{n} \mathrm{Cu}$ clusters. Also listed in Table I are total energies of neutral $\mathrm{Al}_{n} \mathrm{Cu}$ cluster having $\mathrm{Al}_{n} \mathrm{Cu}^{-}$geometry and cationic $\mathrm{Al}_{n} \mathrm{Cu}^{+}$cluster having the neutral ground state geometry. While the difference in the total energies between the ground states of the neutral and anionic clusters provides the adiabatic electron affinity, that between the anion and the neutral with the anion geometry provides the vertical electron affinity. The vertical ionization potential is obtained by calculating the energy difference between the neutral and cationic cluster having the geometry of the neutral. These 
TABLE I. Total energies (a.u.) of $\mathrm{Al}_{n} \mathrm{Cu}$ clusters in neutral and charged configurations for various geometrical forms.

\begin{tabular}{lccccc}
\hline \hline Cluster & $\begin{array}{c}\text { Anion } \\
\text { (optimized) }\end{array}$ & $\begin{array}{c}\text { Neutral } \\
\text { (with anion } \\
\text { geometry) }\end{array}$ & $\begin{array}{c}\text { Neutral } \\
\text { (optimized) }\end{array}$ & $\begin{array}{c}\text { Cation } \\
\text { (with neutral } \\
\text { geometry) }\end{array}$ & $\begin{array}{c}\text { Cation } \\
\text { (optimized) }\end{array}$ \\
\hline $\mathrm{Al}_{11} \mathrm{Cu}$ & -4306.03667 & -4305.93240 & -4305.94126 & -4305.71203 & -4305.71925 \\
$\mathrm{Al}_{12} \mathrm{Cu}$ & -4548.42176 & -4548.31344 & -4548.31482 & -4548.07221 & -4548.07939 \\
$\mathrm{Al}_{13} \mathrm{Cu}$ & -4790.79077 & -4790.69716 & -4790.71110 & -4790.47251 & -4790.47751 \\
$\mathrm{Al}_{14} \mathrm{Cu}$ & -5033.10507 & -5033.00416 & -5033.01364 & -5032.79989 & -5032.80890 \\
\hline \hline
\end{tabular}

energy differences, as well as the HOMO-LUMO gap of the neutral clusters are given in Table II.

Also listed in Table II are the energy gains, $\Delta E$, in adding an $\mathrm{Al}$ atom to an $\mathrm{Al}_{n} \mathrm{Cu}$ cluster. This is defined as

$$
\begin{aligned}
& \Delta E_{n}=-\left[E\left(\mathrm{Al}_{n} \mathrm{Cu}\right)-E\left(\mathrm{Al}_{n-1} \mathrm{Cu}\right)\right]-E(\mathrm{Al}), \\
& \Delta E_{n}^{-}=-\left[E\left(\mathrm{Al}_{n} \mathrm{Cu}^{-}\right)-E\left(\mathrm{Al}_{n-1} \mathrm{Cu}^{-}\right)\right]-E(\mathrm{Al}),
\end{aligned}
$$

where $E$ is the total energy of the respective systems. Note that one of the factors that contributes to the relative peak heights in the mass spectra of clusters is the magnitude of this energy gain. For neutral $\mathrm{Al}_{n} \mathrm{Cu}$ clusters the energy gain, $\Delta E_{n}$ in going from the $\mathrm{Al}_{11} \mathrm{Cu}$ cluster to $\mathrm{Al}_{12} \mathrm{Cu}$ is $3.80 \mathrm{eV}$ while that in going from $\mathrm{Al}_{12} \mathrm{Cu}$ to $\mathrm{Al}_{13} \mathrm{Cu}$ is $4.42 \mathrm{eV}$. The energy gain in going from $\mathrm{Al}_{13} \mathrm{Cu}$ to $\mathrm{Al}_{14} \mathrm{Cu}$ is substantially lower, namely $1.87 \mathrm{eV}$. This suggests that neutral $\mathrm{Al}_{13} \mathrm{Cu}$ should be more abundant than $\mathrm{Al}_{12} \mathrm{Cu}$ and far more abundant than $\mathrm{Al}_{14} \mathrm{Cu}$. This is consistent with the electronic shell closing if one assumes that $\mathrm{Al}_{13} \mathrm{Cu}$ corresponds to a 40 valence electron system. Thus, if $\mathrm{Al}_{n} \mathrm{Cu}$ clusters are born neutral, the enhanced stability of $\mathrm{Al}_{13} \mathrm{Cu}$ would indicate that in the anion mass spectra more of the $\mathrm{Al}_{13} \mathrm{Cu}^{-}$clusters are observed since there are more of them to which the extra electron has attached. In Fig. 2 we reproduce the experimental mass spectra ${ }^{6}$ of $\mathrm{Al}_{n} \mathrm{Cu}^{-}$for clarity. Note that the drop in the intensity from $\mathrm{Al}_{13} \mathrm{Cu}^{-}$to $\mathrm{Al}_{14} \mathrm{Cu}^{-}$is much more than the rise from $\mathrm{Al}_{12} \mathrm{Cu}^{-}$to $\mathrm{Al}_{13} \mathrm{Cu}^{-}$. This is again consistent with the $\Delta E_{n}$ values in Table II. We also note from Table II that $\Delta E_{n}^{-}$for the $\mathrm{Al}_{n} \mathrm{Cu}^{-}$clusters monotonically decreases from $n=12$ to 14 . This clearly is inconsistent with the distribution of mass ion intensities and provides further evidence that the mass ion intensities of $\mathrm{Al}_{n} \mathrm{Cu}^{-}$clusters may be tied to the abundance of the neutral clusters.

In order to understand the effect of $\mathrm{Cu}$ doping on the valence electron energy levels of $\mathrm{Al}_{13}$ vis-à-vis those of $\mathrm{Al}_{13}^{-}$ and $\mathrm{Al}_{13} \mathrm{~K}$. In Fig. 3 we plot the molecular orbital energy

TABLE II. Adiabatic and vertical electron affinities (AEA, VEA), vertical ionization potentials (VIP), HOMO-LUMO gaps, and energy gains $(\Delta E)$ in adding an $\mathrm{Al}$ atom to $\mathrm{Al}_{n-1} \mathrm{Cu}$ clusters.

\begin{tabular}{lcccccccc}
\hline \hline & \multicolumn{3}{c}{$\begin{array}{c}\text { AEA } \\
(\mathrm{eV})\end{array}$} & & & & \multicolumn{2}{c}{$\begin{array}{c}\Delta E \\
(\mathrm{eV})\end{array}$} \\
\cline { 2 - 5 } Cluster & Theor. & Expt. & $\begin{array}{c}\text { VEA } \\
(\mathrm{eV})\end{array}$ & $\begin{array}{c}\text { VIP } \\
(\mathrm{eV})\end{array}$ & $\begin{array}{c}\text { HOMO-LUMO } \\
\text { gap }(\mathrm{eV})\end{array}$ & \multicolumn{2}{c}{ Neutral } & Anion \\
\hline $\mathrm{Al}_{11} \mathrm{Cu}$ & 2.60 & 2.38 & 2.84 & 6.24 & 0.47 & & \\
$\mathrm{Al}_{12} \mathrm{Cu}$ & 2.91 & 2.53 & 2.95 & 6.60 & 0.25 & 3.80 & 4.11 \\
$\mathrm{Al}_{13} \mathrm{Cu}$ & 2.17 & 2.14 & 2.55 & 6.49 & 1.53 & 4.42 & 3.68 \\
$\mathrm{Al}_{14} \mathrm{Cu}$ & 2.49 & 2.56 & 2.75 & 5.82 & 0.39 & 1.87 & 2.19 \\
\hline \hline
\end{tabular}

levels of $\mathrm{Al}_{13}$ and compare those with corresponding levels in $\mathrm{Al}_{13}^{-}, \mathrm{Al}_{13} \mathrm{~K}$, and $\mathrm{Al}_{13} \mathrm{Cu}$. Note that $\mathrm{Al}_{13}$, due to its odd number of electrons, has a spin doublet ground state and consequently there are separate energy levels corresponding to spin up and down electrons. On the other hand, $\mathrm{Al}_{13}^{-}$, $\mathrm{Al}_{13} \mathrm{~K}$, and $\mathrm{Al}_{13} \mathrm{Cu}$ all have 40 valence electrons and their ground state is a spin singlet and hence each energy level contains two (spin $\uparrow$ and $\downarrow$ ) electrons. The HOMO-LUMO gap in $\mathrm{Al}_{13}$ is small, namely $0.49 \mathrm{eV}$. As an electron is attached, the LUMO level of the spin $\downarrow$ orbitals of $\mathrm{Al}_{13}^{-}$gets filled and opens up a large gap $(1.87 \mathrm{eV})$ between the HOMO and LUMO. In $\mathrm{Al}_{13} \mathrm{~K}$, the occupied energy levels have very little $\mathrm{K}$ contribution and the shifting of the energy levels compared to those of $\mathrm{Al}_{13}^{-}$only reflects a small residual "covalent-" like interaction between $\mathrm{K}$ and $\mathrm{Al}_{13}$. The HOMO-LUMO gap in $\mathrm{Al}_{13} \mathrm{~K}$ is very similar (namely 1.81 $\mathrm{eV}$ ) to that of $\mathrm{Al}_{13}^{-}$. The lack of complexity of the occupied energy levels of $\mathrm{Al}_{13} \mathrm{~K}$ in comparison to those of $\mathrm{Al}_{13}$ and its

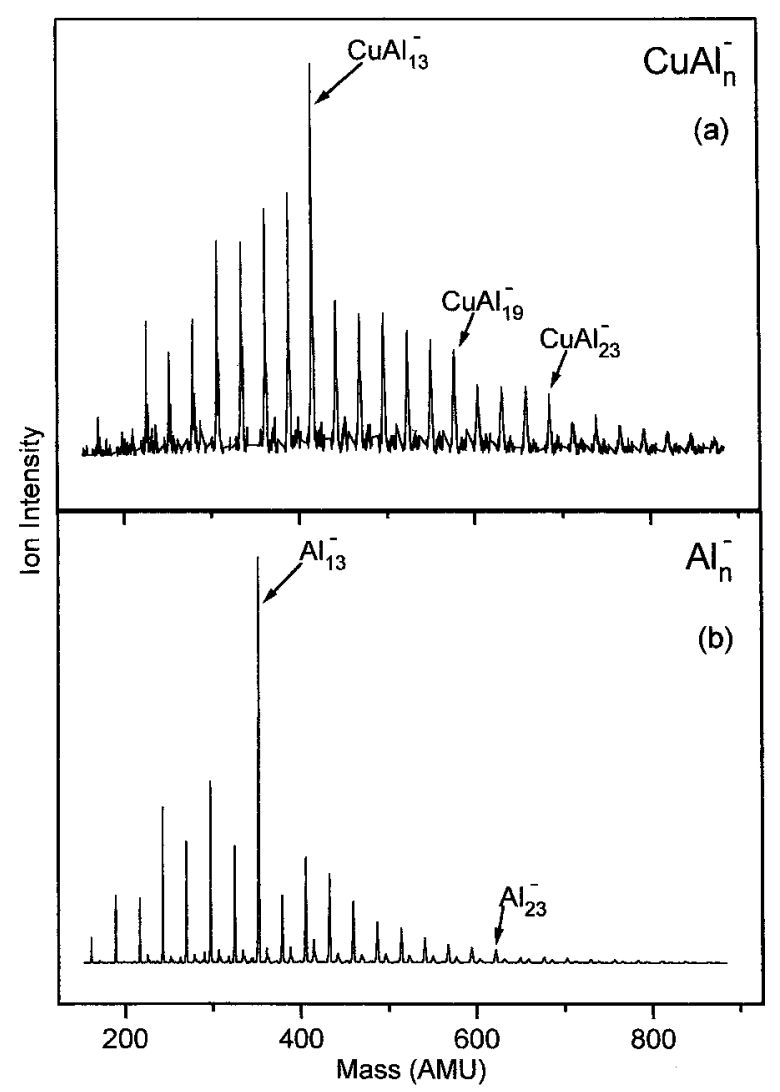

FIG. 2. Experimental mass spectrum of $\mathrm{Al}_{n} \mathrm{Cu}^{-}$vs $\mathrm{Al}_{n}^{-}$clusters (Ref. 6). 


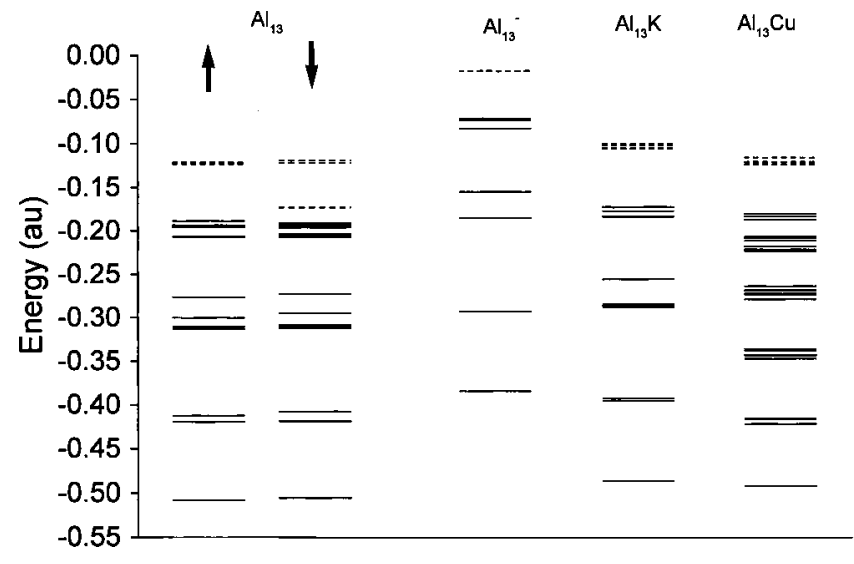

FIG. 3. One electron energy levels of $\mathrm{Al}_{13}, \mathrm{Al}_{13}^{-}, \mathrm{Al}_{n} \mathrm{~K}^{-}$, and $\mathrm{Al}_{n} \mathrm{Cu}^{-}$ clusters.

similarity (except an energy shift) with that of $\mathrm{Al}_{13}^{-}$indicates that in this compound cluster the charge configurations remain close to $\mathrm{Al}_{13}^{-}$and $\mathrm{K}^{+}$, thus a bonding scheme that is very close to being ionic.

The electronic structure of $\mathrm{Al}_{13} \mathrm{Cu}$, on the other hand, is very different. The occupied molecular energy levels of $\mathrm{Al}_{13} \mathrm{Cu}$ contain a lot more states than those in $\mathrm{Al}_{13}^{-}$and $\mathrm{Al}_{13} \mathrm{~K}$. An analysis of the angular character of the occupied energy levels of $\mathrm{Al}_{13} \mathrm{Cu}$ indicates that the states near energies of -0.49 and -0.28 a.u. are derived primarily from $3 d^{10}$ and $4 s^{1}$ electrons of $\mathrm{Cu}$. This strong admixture of the $\mathrm{Cu} 3 d$ and $4 s$ electrons with $3 s$ and $3 p$ electrons of aluminum results because of the high ionization potential of $\mathrm{Cu}$ that makes transferring its $4 s^{1}$ electron to $\mathrm{Al}_{13}$ (as found for $\mathrm{Al}_{13} \mathrm{~K}$ ) energetically difficult. Consequently, the bonding between $\mathrm{Cu}$ and $\mathrm{Al}_{13}$ is more due to charge sharing than due to charge transfer. This is why $\mathrm{Cu}$ prefers to be inside the $\mathrm{Al}_{13}$ cage so that it can form more bonds with Al. On the other hand, the low ionization potential of $\mathrm{K}(4.34 \mathrm{eV})$ makes it easier for it to transfer its electron to $\mathrm{Al}_{13}$ and makes an ionic bond. The strong hybridization of $\mathrm{Cu} 3 d$ and $4 s$ with $\mathrm{Al}_{13}$ valence electrons modifies the simple Jellium-like energy levels of $\mathrm{Al}_{13}^{-}$. The total number of "valence" electrons in the $\mathrm{Al}_{13} \mathrm{Cu}$ neutral cluster is 50, of which 10 electrons belong to the $\mathrm{Cu} 3 d$ states. Thus, the $\mathrm{Al}_{13} \mathrm{Cu}$ cluster still adheres to electronic shell closing although not in the same spirit as the jellium model. Note that there exists a large gap $(1.53 \mathrm{eV})$ between the HOMO and LUMO of $\mathrm{Al}_{13} \mathrm{Cu}$ in spite of the strong hybridization.

In Table II we also list the calculated adiabatic and vertical electron affinities and compare them with available experimental result. Note that the magnitude of the difference between vertical and adiabatic electron affinities is an indication of the difference in the geometry between the ground states of the anion and neutral cluster. These energy differences are about $0.2 \mathrm{eV}$ or less with the exception of $\mathrm{Al}_{13} \mathrm{Cu}$ where structural relaxation following electron detachment from the anion lowers the energy by about $0.4 \mathrm{eV}$. This should give rise to a broadened photodetachment peak in $\mathrm{Al}_{13} \mathrm{Cu}$ compared to neighboring clusters, and this is, indeed, the case. ${ }^{6}$ We also note that the electron affinity (and HOMO-LUMO gap) of $\mathrm{Al}_{13} \mathrm{Cu}$ is smaller (larger) than those of its neighbors-another indication that $\mathrm{Al}_{13} \mathrm{Cu}$ is a closed shell system. We also calculated the vertical ionization potentials (VIPs) of the neutral clusters. These represent the energy it takes to remove an electron from the neutral cluster without relaxing the geometry. Note that both $\mathrm{Al}_{12} \mathrm{Cu}$ and $\mathrm{Al}_{13} \mathrm{Cu}$ have relatively high VIPs. No experimental data are available for comparison.

\section{CONCLUSIONS}

The present work brings out a fundamental difference between the shell closure in $\mathrm{Al}_{13}^{-}, \mathrm{Al}_{13} \mathrm{~K}$, and $\mathrm{Al}_{13} \mathrm{Cu}$ clusters. They all have 40 valence electrons (if we do not include the $10 d$-electrons of $\mathrm{Cu}$ ) and correspond to filled electronic shells in a jellium model. However, the key is to realize that the stability of small clusters is governed not only by the electronic but also by the geometric shell closings. ${ }^{15}$ For $\mathrm{Al}_{n}^{-}$ clusters, the geometric and electronic shell closings occur at $\mathrm{Al}_{13}^{-}$and the mass spectrum of the anionic clusters shows an unusually marked peak. For $\mathrm{Al}_{n} \mathrm{~K}$ clusters, the ionization potential of $\mathrm{K}$ is low, the size of the $\mathrm{K}$ atom is bigger than $\mathrm{Al}$, and the AlK dimer bond is not strong. Consequently, the $\mathrm{K}$ atom in an $\mathrm{Al}_{13} \mathrm{~K}$ cluster occupies an external site and donates an electron to the $\mathrm{Al}_{13}$ motif. The stability of $\mathrm{Al}_{n} \mathrm{~K}$ is then similar to those of the $\mathrm{Al}_{n}^{-}$clusters and the recent experiments ${ }^{5}$ indeed confirm the stability of $\mathrm{Al}_{13} \mathrm{~K}$ in the mass spectrum of $\mathrm{Al}_{n} \mathrm{~K}$ clusters. The case of $\mathrm{Cu}$ is however different. The size of the $\mathrm{Cu}$ atom is comparable to $\mathrm{Al}$, the ionization potential of $\mathrm{Cu}$ is high, and the $\mathrm{AlCu}$ dimer bond is strong with a bond strength higher than even the $\mathrm{Al}_{2}$ bond. The $\mathrm{Cu}$ atom then occupies an interior site and there is considerable mixing between the electronic states of $\mathrm{Cu}$ and $\mathrm{Al}$. This leads to a strange situation in $\mathrm{Al}_{n} \mathrm{Cu}$ clusters. While the geometric shell closure occurs at $\mathrm{Al}_{12} \mathrm{Cu}$, the electronic shell closure occurs at $\mathrm{Al}_{13} \mathrm{Cu}$. This is the reason that in anionic clusters, $\mathrm{Al}_{12} \mathrm{Cu}^{-}$has a higher $\Delta E$ (Table II) than $\mathrm{Al}_{13} \mathrm{Cu}^{-}$. On the other hand, in neutral clusters, the electronic shell closure leads to a higher $\Delta E$ for $\mathrm{Al}_{13} \mathrm{Cu}$ than for $\mathrm{Al}_{12} \mathrm{Cu}$. This interplay between geometric and electronic closings is most transparent in the ionization where $\mathrm{Al}_{12} \mathrm{Cu}$ and $\mathrm{Al}_{13} \mathrm{Cu}$ both have a high VIP. It would be interesting to carry out experiments on other $\mathrm{Al}_{n} \mathrm{X}$ clusters with atoms belonging to the same column of the periodic table to see how the size would affect the stability of the clusters.

\section{ACKNOWLEDGMENTS}

This work was supported in part by a grant from the Department of Energy (No. DEFG02-96ER45579). We thank Professor K. Bowen for suggesting this problem and for sharing their experimental data prior to publication.

${ }^{1}$ W. D. Knight, K. Clemenger, W. A. de Heer, W. A. Saunders, M. Y. Chou, and M. L. Cohen, Phys. Rev. Lett. 52, 2141 (1984); S. Saito and S. Ohnishi, ibid. 59, 190 (1980).

${ }^{2}$ Small Particles and Inorganic Clusters, edited by H. H. Anderson (Springer, New York, 1997).

${ }^{3}$ S. N. Khanna and P. Jena, Chem. Phys. Lett. 219, 479 (1994); H.-P. Cheng, R. N. Barnett, and U. Landman, Phys. Rev. B 48, 1820 (1993); C. Ashman, S. N. Khanna, M. R. Pederson, and J. Kortus, ibid. 62, 16956 (2000). 
${ }^{4}$ B. K. Rao and P. Jena, J. Chem. Phys. 113, 1508 (2000).

${ }^{5} \mathrm{~K}$. H. Bowen (private communication).

${ }^{6}$ O. C. Thomas, W. Zheng, and K. H. Bowen, J. Chem. Phys. (in press).

${ }^{7}$ R. E. Leuchtner, A. C. Harms, and A. W. Castleman, Jr., J. Chem. Phys. 94, 1093 (1991).

${ }^{8}$ M. M. Kappes, M. Schar, P. Radi, and E. Schumacher, Chem. Phys. Lett. 119, 11 (1985).

${ }^{9}$ S. B. Zhang, M. L. Cohen, and M. Y. Chou, Phys. Rev. B 36, 3455 (1987); C. Yannouleas, P. Jena, and S. N. Khanna, ibid. 46, 9751 (1992).
${ }^{10}$ W. J. Hehre, L. Radom, P. von R. Schleyer, and J. A. Pople, Ab Initio Molecular Orbital Theory (Wiley, New York, 1986).

${ }^{11}$ J. P. Perdew, K. Burke, and M. Ernzerhof, Phys. Rev. Lett. 77, 3865 (1996).

${ }^{12}$ M. R. Pederson and K. A. Jackson, Phys. Rev. B 41, 7453 (1990); K. A. Jackson and M. R. Pederson, ibid. 42, 3276 (1990).

${ }^{13}$ D. V. Porezag and M. R. Pederson, Phys. Rev. A 60, 2840 (1999).

${ }^{14}$ B. K. Rao, S. N. Khanna, and P. Jena, Phys. Rev. B 62, 4666 (2000).

${ }^{15}$ S. N. Khanna and P. Jena, Phys. Rev. Lett. 69, 1664 (1992); Phys. Rev. B 51, 13705 (1995); S. N. Khanna, B. K. Rao, and P. Jena (unpublished). 